\title{
Primary school teachers are at risk to suffer from dysphonia
}

Esther Rishma Sundram ${ }^{\text {* }}$

Norsa Adah Bachok b

Mohd Ismail Ibrahim ${ }^{c}$

Nik Rosmawati Nik Husain d

Hazama Mohamad e

Foong Ming Moy ${ }^{f}$

Mohd Nazri Shafei ${ }^{g}$

Suggested Citation:

Abstract 
1. Introduction 
2. Material and Methods

\section{Results}

Table 1: Prevalence of Dysphonia and Characteristics Of The respondents $(n=331)$ 
Table 2: Descriptive characteristics of possible associated factors by dysphonia and non-dysphonia groups ( $n=331$ ) 
Table 3: Association between sociodemographic and occupational factors with dysphonia among primary school teachers in a northeastern district in Malaysia $(n=331)$

Table 4: Associated factors of dysphonia among primary school teachers in a district in northeastern Malaysia using multiple logistic regression $(n=331)$

4. Discussion 


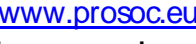


5. Conclusion

Acknowledgement 
References 